\title{
Thermodynamic forward modeling of retrogressive hydration reactions induced by geofluid infiltration
}

\author{
Tatsu Kuwatani ${ }^{1,2^{*}}$ (1) and Mitsuhiro Toriumi ${ }^{3}$
}

\begin{abstract}
We have developed a new methodology for forward analysis of retrogressive hydration (rehydration) reactions by an improved thermodynamic forward modeling technique based on a differential thermodynamic approach (Gibbs' method). Based on natural observations and theoretical considerations, the progress of a rehydration reaction is modeled by incorporating a change in the effective bulk composition on account of the breakdown of the nonequilibrated phase and the amount of water infiltration into the system. Forward analyses of rehydration reactions under greenschist-facies conditions show that (1) the reaction progress of rehydration is proportional to the external water supply, and (2) the mineral compositions of equilibrated minerals are mainly controlled by $P-T$ conditions and are similar to those in the global equilibrium model. Calculated results are in accordance with natural observations of rehydration reactions in greenschist-facies rocks, which supports the validity of the proposed model. The proposed model can be used as a basic forward model for various inversion analyses and numerical simulations and thus to understand the distribution and behavior of geofluids.
\end{abstract}

Keywords: Rehydration, Forward modeling, Greenschist, Geofluid

\section{Introduction}

Retrogressive hydration metamorphism may be a key process for understanding the behavior and distribution of geofluids and various related geodynamic processes, such as water budgets, seismicity, and the exhumation of metamorphic belts. This is because retrogressive hydration (hereafter termed rehydration) may exert a major influence on geofluid fluxes and on physical and chemical rock properties (e.g., Andersen et al. 1991; Jamtveit et al. 2000; Yardley 2009; Uno et al. 2014). Metamorphic rocks that have undergone rehydration offer unique and direct insights into geofluid behavior.

In recent studies, forward modeling methods, such as those used to generate pseudosections and in differential thermodynamic modeling, have proven useful because they can thermodynamically predict mineral modes and

\footnotetext{
*Correspondence: kuwatani@jamstec.go.jp

${ }^{1}$ Department of Solid Earth Geochemistry, Japan Agency for Marine-

Earth Science and Technology (JAMSTEC), 2-15 Natsushima-cho,

Yokosuka 237-0061, Japan

Full list of author information is available at the end of the article
}

compositions for given $P-T$ conditions and bulk compositions (e.g., Powell et al. 1998; Omori et al. 2002, 2009; Inui and Toriumi 2004; Connolly 2009; Capitani and Petrakakis 2010). For example, forward modeling methods can generally reproduce mineral assemblages and compositions of rocks subject to prograde or peak-stage metamorphism and have been successfully used to predict the depths at which dehydration reactions occur (e.g., Kerrick and Connolly 2001; Hacker et al. 2003).

On the other hand, a comparatively small number of these forward models have been able to model reactions that proceed during the retrograde stage of metamorphism, such as rehydration reactions (Stüwe 1997; Kohn and Spear 2000; Guiraud et al. 2001; Wei and Clarke 2011; Palin et al. 2014). The limitations of the forward models are due to some important differences between the conditions and behavior of prograde dehydration and retrograde rehydration reactions, even though rehydration is simply a reverse dehydration reaction. Rehydration reactions commonly proceed heterogeneously in a non-equilibrium state (e.g., Brodie and Rutter 1985; 
Plunder et al. 2012), whereas dehydration reactions occur under relatively homogeneous conditions in a perfect equilibrium state. As described in detail in the next section, rehydration reactions are generally fluid-induced and occur via replacement of relict minerals by equilibrated minerals (e.g., Andersen et al. 1991; Imon et al. 2002; Ota et al. 2004; Okamoto and Toriumi 2005; Putnis 2009; Putnis and Austrheim 2010; Centrella et al. 2015).

The purpose of this study is to develop a new method of forward analysis of retrogressive hydration reactions by improving the differential thermodynamic forward modeling approach (Inui and Toriumi 2004; Kuwatani et al. 2011; Spear 1993). In the formulation, mass-balance equations were modified to take into account the effect of non-equilibrated minerals and water supply. The main difference between the proposed method and previous equilibrium models of rehydration metamorphism, which depict $P-T-M\left(\mathrm{H}_{2} \mathrm{O}\right)$ diagrams (e.g., Guiraud et al. 2001; Wei and Clarke 2011; Palin et al. 2014), is that our model can accommodate changes in effective bulk compositions, and not just as assumed input parameters. The changes in mineral modes and compositions can be estimated for given $P-T$ conditions and amounts of external water infiltration, which is why our method can be regarded as an autonomous forward modeling approach.

Firstly, we describe how rehydration reactions proceed based on theoretical considerations (Guiraud et al. 2001; Putnis 2009; Putnis and Austrheim 2010) and natural observations of metamorphic rocks (Andersen et al. 1991; Imon et al. 2002; Okamoto and Toriumi 2005; Yang 2004; Centrella et al. 2015). Secondly, forward modeling of rehydration is formulated by applying the thermodynamic forward modeling approach proposed by Kuwatani et al. (2011). Thirdly, the forward modeling technique is applied to rehydration of high-grade greenschist rocks. Finally, we assess the validity and effectiveness of our forward modeling by comparing calculated results with the natural examples of Okamoto and Toriumi (2005). In addition, we discuss the role of geofluid behavior on rehydration metamorphism.

In this study, we focus on pure water $\left(\mathrm{H}_{2} \mathrm{O}\right)$ as a geofluid and assume that the water activity equals 1 . However, in order to understand the geofluid behavior in detail, other components, such as $\mathrm{CO}_{2}$ and $\mathrm{NaCl}$, are also important. Although some extensions are required to deal with a multi-component fluid, the proposed model can serve as a basic framework for forward models.

\section{Rehydration reactions}

If a rock system is consistently and completely in equilibrium (hereafter termed as being in 'global equilibrium'), the mineral assemblages, modes, and compositions will converge continuously toward an equilibrium state as
$P-T$ conditions change. In this case, no relict minerals are present in the system, which is at global equilibrium. However, real rock systems are mostly in various nonequilibrium states, particularly during retrograde stages (when rehydration reactions generally occur), and in which intrinsically unstable minerals are often preserved as relict minerals. Subsequently, we refer to these unstable minerals, which include dissolving and metastable phases and phases not involved in reactions, as non-equilibrium minerals.

One of the fundamental reasons for the prevalence of non-equilibrium conditions is considered to be related to the deficiency of water during the retrograde stage. Firstly, rehydration reactions generally require an external supply of water or breakdown of hydrous minerals sufficient to produce low-temperature hydrous minerals (e.g., Yardley et al. 2014; Vitale Brovarone and Beyssac 2014; Palin et al. 2014). Secondly, rehydration reactions are generally volume expanding, which slows down the external supply of water by closing preexisting fluid pathways, if external stress is absent (e.g., Okamoto and Shimizu 2015). Thirdly, the rates of reaction processes (e.g., intra-/intergrain diffusion, nucleation, and surface processes) are hindered by the deficiency of metamorphic fluids as well as being strongly controlled by temperature (e.g., Rubie 1986; Austrheim 1987).

During the prograde stage, dehydration reactions may proceed spontaneously, because both the increase in temperature and the presence of $\mathrm{H}_{2} \mathrm{O}$-saturated conditions kinetically promote the progress of the reactions. Thus, equilibrium is easily attained relative to rehydration reactions, although it should be noted that there are some exceptions and that even prograde dehydration reactions can be induced by external fluids (e.g., Gao and Klemd 2001). In contrast, during the retrograde stage, both the decrease in temperature and the presence of $\mathrm{H}_{2} \mathrm{O}$-undersaturated conditions kinetically hinder the progress of rehydration reactions, and thus, equilibrium is difficult to achieve (Stüwe 1997). When a rock is fluid-free, rehydration reactions never occur, unless free water is supplied externally or retrograde breakdown of hydrous minerals occurs, as hydrous minerals such as lawsonite and talc contain large amounts of water (Palin et al. 2014). This is because rehydration reactions generally require water to produce low-temperature hydrous minerals (e.g., Yardley et al. 2014). Therefore, retrogressive metamorphism is generally considered to be fluidinduced (e.g., Andersen et al. 1991; Putnis and Austrheim 2010), such that the driving forces of rehydration can be assumed to be water infiltration in addition to changes in temperature and pressure.

In retrogressed metamorphic rocks, many disequilibrium textures related to incomplete hydration reactions 
are present, including partial pseudomorphic textures. From these textures, rehydration reactions are commonly considered to proceed under non-equilibrium conditions with the decomposition or replacement of nonequilibrium components, such as unstable minerals or the unstable portions of minerals that are components of stable mineral assemblages (e.g., Vernon 2004; Ota et al. 2004; Okamoto and Toriumi 2005; Putnis 2009; Putnis and Austrheim 2010; Putnis and John 2010). For example, higher-grade non-equilibrium minerals such as garnet, omphacite, and kyanite are decomposed to produce lower-grade minerals such as amphibole, plagioclase, and paragonite (e.g., Yang 2004).

The mechanism of replacement reactions generally involves coupling of dissolution and precipitation at the interfaces of non-equilibrated minerals (e.g., Imon et al. 2002; Okamoto and Toriumi 2005; Putnis 2009; Putnis and Austrheim 2010; Centrella et al. 2015). Figure 1 shows a retrogressed mafic schist in a metamorphic rock from the Sanbagawa metamorphic belt in SW Japan. The Sanbagawa metamorphism is of the high-pressure intermediate type (e.g., Miyashiro 1961) and considered to have formed by the subduction and exhumation of the Izanagi oceanic plate beneath eastern Asia (e.g., Wallis et al. 2009). A detailed petrological description is given in Additional file 1. By detailed microtextural observations and mass-balance calculations, Okamoto and Toriumi (2005) revealed that actinolite and lower-grade metamorphic minerals grow in association with congruent dissolution of core barroisite, which remained as a nonequilibrated phase. In low-temperature metamorphic conditions, such replacement reactions generally proceed without changing the compositions of reactant minerals, which is known as congruent dissolution.

\section{Formulation of the forward analysis}

In a previous study (Kuwatani et al. 2011), differential thermodynamic forward modeling of dehydration reactions was formulated with the assumption of global equilibrium. In this study, the model is extended to analyze rehydration reactions. The proposed model is not a kinetic forward model but a practical forward model based on phase equilibrium and mass balance.

In differential thermodynamic forward modeling, three types of equations (i.e., those with thermodynamic equilibrium, stoichiometric, and mass-balance constraints) are expressed in total differential form (Spear 1993). A thermodynamic system with a fixed bulk chemical composition is divariant, as specified by Duhem's theorem. Therefore, by applying a series of changes in pressure $d P$ and temperature $d T$ as independent variables or model parameters as initial conditions, we can continuously trace the chemical compositions of minerals $d X \mathrm{~s}$

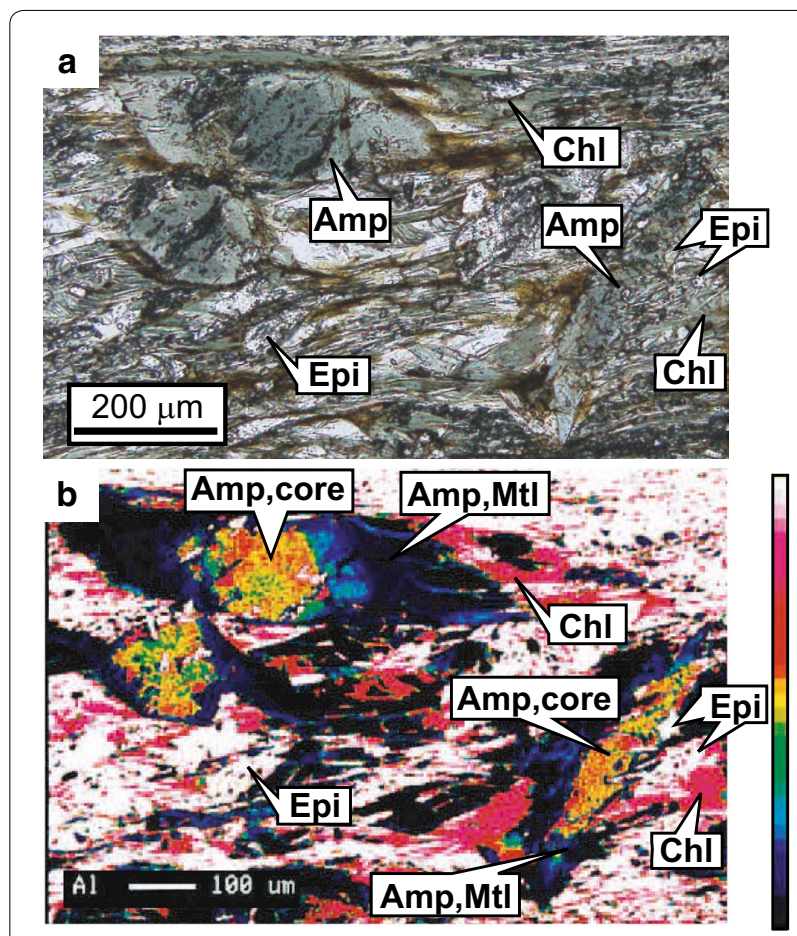

Fig. 1 a Microphotograph in plane polarized light and $\mathbf{b}$ X-ray map of Al concentrations showing the characteristics of retrogressed mafic schist in the Sanbagawa metamorphic belt. In amphibole grains (Amp), the Al-rich core (Amp, core) is barroisite, whereas the Al-poor mantle (Amp, Mtl) is actinolite. Microstructural observations indicate that actinolite and lower-grade metamorphic minerals such as epidote (Epi) and chlorite (Chl) grew at the expense of core barroisite, which is a non-equilibrated phase (Okamoto and Toriumi 2005) (for more details, see Additional file 1). Note: this X-ray map was kindly provided by Dr. A. Okamoto

and mineral modes $d M \mathrm{~s}$ as dependent variables and thus the progress (evolution) of metamorphic reactions along arbitrary $P-T$ trajectories.

In the application of forward modeling to rehydration reactions, the various complexities that were described in the previous sections must be considered. In this study, the following two factors are considered to be the most important characteristics of rehydration reactions and are incorporated into the forward modeling. The first is the dependency of reaction progress on the amount of available water. The second is the modification of the effective bulk composition by the decrease in the abundance of non-equilibrated minerals as the reaction proceeds. These effects do not directly affect the equilibrium or the stoichiometric constraints, both of which involve only the compositions and modes of equilibrium minerals. Therefore, the equilibrium and stoichiometric constraints can be written in the same form as in the model for dehydration reactions [Eqs. (1) and (5) of Kuwatani et al. (2011)]. Thus, the model of rehydration 
reactions only requires modification of the mass-balance equations.

Firstly, the system is assumed to be partially open only for the $\mathrm{H}_{2} \mathrm{O}$ component, and we assume that the amount of water infiltration $d m_{\mathrm{H}_{2} \mathrm{O}}$ is an input parameter. In Kuwatani et al. (2011), $d M^{\text {Water }}$ was used as an outputdependent parameter to monitor the amount of water production by dehydration reactions. In this study, we assume that the free water that infiltrates the system is immediately fixed within equilibrated hydrous minerals, such that $d M^{\text {Water }}=0$, which results in the amount of water always being zero $\left(M^{\text {Water }}=0\right)$. In other words, $d m_{\mathrm{H}_{2} \mathrm{O}}$ is regarded as the amount of water consumption by rehydration reactions. This assumption is considered to be valid with respect to retrograde metamorphism according to previous kinetic experiments (Yardley et al. 2014) and natural observations, as discussed above.

The value of $d m_{\mathrm{H}_{2} \mathrm{O}}$ is given as a new independent variable, in addition to $d P$ and $d T$, to investigate the effects of external water infiltration into the system on the progress of the rehydration reactions. The introduction of a given amount of water into the system in the thermodynamic calculations has already been studied in previous research Guiraud et al. (2001), Palin et al. (2014), Wei and Clarke (2011) that depict the process on $P-T-M_{\mathrm{H}_{2} \mathrm{O}}$ pseudosection diagrams.

Secondly, we add the total amount of non-equilibrium minerals $\left(d M^{\mathrm{NE}}\right)$ as a dependent variable, in order to consider the existence of relict non-equilibrated phases and their effects on the effective bulk composition. For equilibrated minerals, the mass-balance equations are the same as those used in previous dehydration models. Stüwe (1997) considered changes in the effective bulk composition, which was derived from slow diffusion due to cooling in the retrograde stage. In our study, congruent dissolution is assumed in the decrease in non-equilibrium minerals, such that compositions of non-equilibrated minerals are set to be constant. For component $i$, the modified mass-balance equations can be written as

$$
\begin{aligned}
d m_{i} & =\sum_{k=1}^{n p h} M^{k} \sum_{j=1}^{n p c^{k}} n_{i, j}^{k} d X_{j}^{k}+\sum_{k=1}^{n p h} d M^{k} \sum_{j=1}^{n p c^{k}} n_{i, j}^{k} X_{j}^{k} \\
& +d M^{\mathrm{NE}} \sum_{j=1}^{n p c^{\mathrm{NE}}} n_{i, j}^{\mathrm{NE}} X_{j}^{\mathrm{NE}}
\end{aligned}
$$

where $n p h$ is the number of equilibrium phases, $n p c^{k}$ is the number of phase components in every mineral phase $k, n_{i, j}^{k}$ is the number of moles of system component $i$ in one mole of each phase component $j, d m_{i}, d M^{k}$, and $d X_{j}^{k}$ are molar changes in system component $i$ and of phase $k$, and the change in mole fraction of component $j$ in phase $k$, respectively. The superscript 'NE' denotes a non-equilibrium mineral, a set of non-equilibrium minerals, or the non-equilibrium parts of minerals.

The first and second terms for equilibrated minerals in the right-hand side of Eq. 1 are of the same form as those used for the modeling of dehydration. These terms describe a case in which each phase has a homogeneous composition at every stage, and the composition varies according to external conditions ( $P, T$, etc.). On the other hand, the last term indicates the change in the effective bulk composition of the system due to the reduction in the non-equilibrium part. The term for $d X^{\mathrm{NE}}$ in the equation is absent, as the compositions of the non-equilibrium part are assumed to be constant. The above mass-balance equations indicate that decomposition of relict minerals changes the effective bulk composition and provides materials for growing equilibrium minerals (Fig. 2).

Under the assumption of a closed system other than for the $\mathrm{H}_{2} \mathrm{O}$ component as $d m_{i}=0\left(i \neq \mathrm{H}_{2} \mathrm{O}\right)$, the system of equations for the forward modeling still remains solvable, if the compositions of non-equilibrium parts are known. This is because the additional degree of freedom associated with the dependent variable and the total amount of non-equilibrium mineral $\left(d M^{\mathrm{NE}}\right)$ is compensated for by the additional input parameter, which is the amount of infiltrated water $d m_{\mathrm{H}_{2} \mathrm{O}}$. Thus, in this model, we can simulate the reduction in the non-equilibrated part (relict minerals and interior parts of zoned minerals) and the growth of equilibrated minerals in response to $d m_{\mathrm{H}_{2} \mathrm{O}}, d P$, and $d T$ during retrograde metamorphism. The proposed model can also be applied to open-system behavior. By inputting the amount of material transfer for each component $d m_{i}$, the mineral modes and compositions can be specified in the same way as in a closed system. Open-system behavior is important, particularly for rehydration metamorphism, and it should be investigated in future studies to facilitate an understanding of geofluid distribution and behavior.

\section{Application to actinolite-forming reactions under greenschist-facies conditions}

To understand how rehydration reactions proceed in natural systems, assess the role of geofluid infiltration in rehydration metamorphism, and check the validity of our model, we simulated rehydration of a high-grade greenschist rock under greenschist-facies conditions. The greenschist-facies occupies a wide range of crustal $P-T$ conditions and is well suited for understanding the role of geofluid infiltration on rehydration metamorphism. In addition, we have already modeled dehydration 


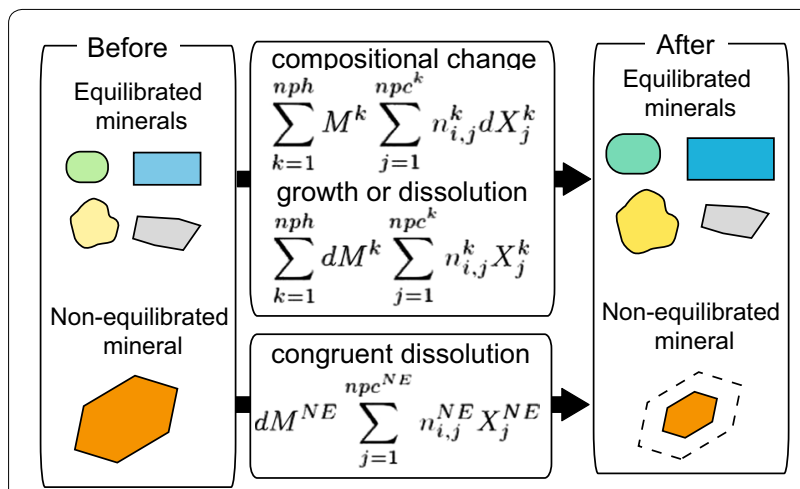

Fig. 2 Conceptual schematic of the mass-balance equations, including the non-equilibrium phase (Eq. 1). The first and second terms on the right-hand side of Eq. 1 indicate the compositional and modal changes, respectively, of the equilibrated minerals. The third term on the right-hand side of the equation indicates the modal changes caused by congruent dissolution of non-equilibrated minerals

reactions in greenschist-facies rocks (Kuwatani et al. 2011). Therefore, our models are well suited for examining greenschist-facies conditions and the differences between dehydration and rehydration processes. We can also compare our numerical results with those of natural metamorphic rocks, as described in Okamoto and Toriumi (2005).

\section{Formulation}

In the forward model for prograde dehydration reactions (Kuwatani et al. 2011), the system is assumed to consist of amphibole + epidote + chlorite + plagioclase + quartz + water in the system of $\mathrm{Na}_{2} \mathrm{O}-\mathrm{CaO}-\mathrm{MgO}-\mathrm{FeO}-$ $\mathrm{Fe}_{2} \mathrm{O}_{3}-\mathrm{Al}_{2} \mathrm{O}_{3}-\mathrm{SiO}_{2}-\mathrm{H}_{2} \mathrm{O}$ according to Okamoto and Toriumi (2001, 2004). Within greenschist-facies rocks, it is assumed that the amounts of minor minerals, such as mica and titanite, are relatively small as compared with the assumed amounts of the main constituent minerals (e.g., Hacker et al. 2003; Okamoto and Toriumi 2005).

In this rehydration model, amphiboles are classified into two components according to field observations of the Sanbagawa metabasalts (Okamoto and Toriumi 2005), such that the system is assumed to consist of mantle amphibole + core amphibole + epidote + chlorite + plagioclase + quartz + water in the system $\mathrm{Na}_{2} \mathrm{O}-\mathrm{CaO}-$ $\mathrm{MgO}-\mathrm{FeO}-\mathrm{Fe}_{2} \mathrm{O}_{3}-\mathrm{Al}_{2} \mathrm{O}_{3}-\mathrm{SiO}_{2}-\mathrm{H}_{2} \mathrm{O}$. Mantle amphibole grows during retrogressive metamorphism and has equilibrium compositions, whereas core amphibole is a relict phase and has non-equilibrium compositions (Fig. 1). In this case, core amphibole that has the original composition prior to rehydration metamorphism is considered as the 'non-equilibrium mineral' in the model.

In a closed system, the mass-balance equation for component $i$ can be written as:

$$
\begin{aligned}
d m_{i} & =\sum_{k=1}^{n p h-1} M^{k} \sum_{j=1}^{n p c^{k}} n_{i, j}^{k} d X_{j}^{k}+\sum_{k=1}^{n p h-1} d M^{k} \sum_{j=1}^{n p c^{k}} n_{i, j}^{k} X_{j}^{k} \\
& +M^{A m p, M t l} \sum_{j=1}^{n p c^{A m p, M t l}} n_{i, j}^{A m p, M t l} d X_{j}^{A m p, M t l} \\
& +d M^{A m p, M t l} \sum_{j=1}^{n p c^{A m p, M t l}} n_{i, j}^{A m p, M t l} X_{j}^{A m p, M t l} \\
& +d M^{\text {Amp,core }} \sum_{j=1}^{n p c^{A m p, c o r e}} n_{i, j}^{\text {Amp,core }} X_{j}^{A m p, \text { core }}
\end{aligned}
$$

where $M^{A m p, M t l}$ is the molar amount of amphibole that has the equilibrium composition $X_{j}^{A m p, M t l}$ and $d M^{A m p, c o r e}$ is the change in the molar amount of amphibole that has the constant non-equilibrium composition $X_{j}^{A m p, c o r e}$.

We can simulate the growth of equilibrated minerals, such as low-grade amphibole, epidote, chlorite, plagioclase, and quartz, and the decomposition of the original high-grade amphibole, according to changes in $d T, d P$, and the amount of water infiltration $d m_{\mathrm{H}_{2} \mathrm{O}}$, under the assumption of a closed system for other components as $d m_{i\left(\neq \mathrm{H}_{2} \mathrm{O}\right)}=0$. In this study, we calculated changes in the mineral modes and compositions for the following four representative cases, as presented in Fig. 3.

To evaluate reaction progress corresponding to $P-T$ changes, we conducted calculations along the retrograde $P-T$ path from $500{ }^{\circ} \mathrm{C}$ and $1.0 \mathrm{GPa}$ for the following two

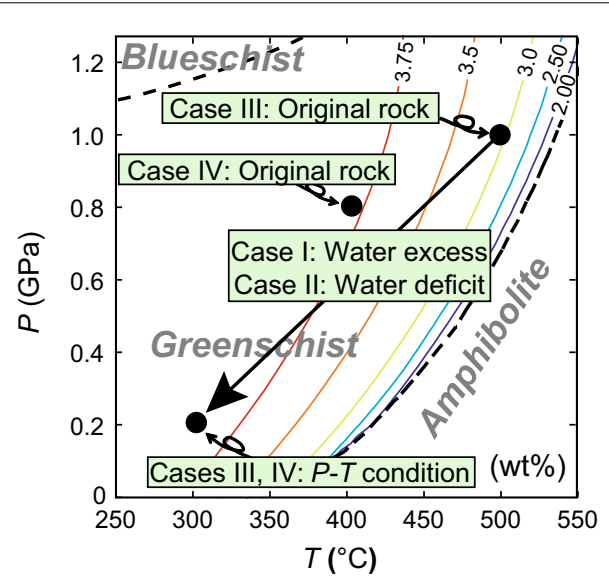

Fig. 3 The $P-T$ conditions used in the calculations. For cases I and II, the applied $P-T$ path is from $500{ }^{\circ} \mathrm{C}$ and $1.0 \mathrm{GPa}$ to $300^{\circ} \mathrm{C}$ and $0.2 \mathrm{GPa}$. For cases III and IV, the applied $P-T$ condition is $300^{\circ} \mathrm{C}$ and $0.2 \mathrm{GPa}$. The equilibrated condition of the original rocks was set to $500^{\circ} \mathrm{C}$ and 1.0 GPa for case III and $400^{\circ} \mathrm{C}$ and $0.8 \mathrm{GPa}$ for case IV. The $P-T$ diagram was modified after Kuwatani et al. (2011). The colored contours indicate the water contents (weight\%) of the globally equilibrated rock 
end-member cases. For case I, water infiltration $d m_{\mathrm{H}_{2} \mathrm{O}}$ is assumed to be sufficient to satisfy the condition that water is always an excess phase $\left(d M^{\text {water }} \geq 0\right)$. For case II, $d m_{\mathrm{H}_{2} \mathrm{O}}$ is assumed to be close to zero $\left(d m_{\mathrm{H}_{2} \mathrm{O}} \simeq 0\right)$, which represents the case in which water is deficient in the system. However, we allowed a small amount of water infiltration to avoid the impossible situation that the growth of mantle amphibole is less than zero $\left(d M^{A m p, M t l} \leq 0\right)$. As a result, the obtained $d m_{\mathrm{H}_{2} \mathrm{O}}$ is less than $1 \%$ of water infiltration, which is required for water excess and that satisfies the condition that water is deficient $\left(d m_{\mathrm{H}_{2} \mathrm{O}} \simeq 0\right)$.

To evaluate reaction progress corresponding to the amount of water infiltration, we conducted calculations with increasing amounts of water infiltration at constant $P-T$ condition of $300{ }^{\circ} \mathrm{C}$ and $0.2 \mathrm{GPa}$. Two cases were considered to assess the effect of the initial setting. In case III, the initial rock was assumed to be in an equilibrated condition at $500{ }^{\circ} \mathrm{C}$ and $1.0 \mathrm{GPa}$. In case IV, the initial rock was assumed to be at $400{ }^{\circ} \mathrm{C}$ and $0.8 \mathrm{GPa}$.

Whole-rock compositions are based on those of natural greenschists with MORB-like compositions (Hacker et al. 2003) and a mineral assemblage of amphibole + epidote + chlorite + plagioclase + quartz + water. Detailed information is given in Additional file 1. The initial mineral composition and the mole fractions at $500{ }^{\circ} \mathrm{C}$ and 1.0 GPa and at $400{ }^{\circ} \mathrm{C}$ and $0.8 \mathrm{GPa}$ were taken from the calculated results of Kuwatani et al. (2011). The compositions of original amphiboles at $500{ }^{\circ} \mathrm{C}$ and $1.0 \mathrm{GPa}$ and at $400{ }^{\circ} \mathrm{C}$ and $0.8 \mathrm{GPa}$ are barroisite and winchite, respectively. The thermodynamic parameters used in the calculations are also those specified in Kuwatani et al. (2011), based mainly on Holland and Powell (1998). It should be noted that the proposed model does not use enthalpy data sets, which are considered to contain large errors, because our model is based on the differential thermodynamic approach (Gibbs' method) (Spear 1993).

\section{Results}

Figure 4a, b illustrates the modal and compositional changes in equilibrated mantle amphibole along the applied $P-T$ path for the two end-member cases I and II, respectively. In case I, core amphibole with a barroisite composition completely breaks down under all $P-T$ conditions, except for the initial conditions, and low-grade minerals, such as mantle amphibole, epidote, chlorite, and plagioclase, grow at the expense of the core amphibole. The composition of mantle amphibole is barroisite at temperatures greater than $400{ }^{\circ} \mathrm{C}$, and hornblende to actinolite at temperatures less than $400{ }^{\circ} \mathrm{C}$. The mineral modes and compositions at each $P-T$ condition are identical to those observed in the forward modeling calculations for dehydration in Kuwatani et al. (2011), which indicates global equilibrium conditions, and that rehydration processes are identical to dehydration processes if water infiltration creates conditions of water excess, such that we can ignore kinetic effects.

In case II, on the other hand, mineral modes remain unchanged, despite changes in $P-T$ conditions. Decomposition of core amphibole is minimal and results in little growth of mantle amphibole or other low-grade minerals. Although mineral modes remain unchanged, the compositions of equilibrated minerals change with the $P-T$ conditions, in a similar fashion as observed in case I. Thus, exchange reactions occur, whereas no net transfer reactions occur under conditions of water deficit.

Figure 4c, d illustrates the modal and compositional changes in equilibrated mantle amphibole under constant $P-T$ conditions $\left(300^{\circ} \mathrm{C}\right.$ and $0.2 \mathrm{GPa}$ ) for cases III and IV, respectively. For both cases, core amphibole decreases, and mantle amphibole, epidote, chlorite, and plagioclase increase in proportion to the water supply $\left(d m_{\mathrm{H}_{2} \mathrm{O}}\right)$. This indicates that core amphibole is consumed to produce mantle amphibole and other low-temperature minerals, and the extent of net transfer in the reaction is in proportion to the water supply. The compositions of the equilibrated minerals vary slightly according to changes in the amount of water, but are approximately the same as those observed in the forward analyses of dehydration reactions in every case. In case III, in which the initial rock is equilibrated at higher temperatures $\left(500{ }^{\circ} \mathrm{C}\right.$ and $\left.1.0 \mathrm{GPa}\right)$, the amount of water infiltration required to consume all of the core amphibole is approximately 1.9 mol per 1000 $\mathrm{cm}^{3}$ of rock. The obtained stoichiometric relation of the rehydration reaction is:

$$
\begin{gathered}
\text { 1Barroisite }+0.81 \text { Quartz }+1.27 \mathrm{H}_{2} \mathrm{O} \\
\longrightarrow 0.22 \text { Actinolite }+0.58 \text { Epidote } \\
+0.44 \text { Chlorite }+0.77 \text { Plagioclase. }
\end{gathered}
$$

In case IV, where the initial temperature is lower $\left(400{ }^{\circ} \mathrm{C}\right.$ and $0.8 \mathrm{GPa}$ ), the amount of water infiltration required to consume all of the core amphibole is approximately 0.16 mol per $1000 \mathrm{~cm}^{3}$ of rock. The obtained stoichiometric relation is:

$$
\begin{aligned}
& 1 \text { Winchite }+0.02 \text { Epidote }+0.37 \mathrm{Quartz}+0.25 \mathrm{H}_{2} \mathrm{O} \\
& \longrightarrow 0.73 \text { Actinolite }+0.13 \text { Chlorite }+0.65 \text { Plagioclase }
\end{aligned}
$$

The large discrepancy in the amount of water infiltration required to consume all of the core amphibole in the high-temperature versus low-temperature original rocks is directly related to the difference in the initial amount of water, as the equilibrated amount of water fixed in the minerals is the same as that in the final state $\left(300{ }^{\circ} \mathrm{C}\right.$ and $0.2 \mathrm{GPa}$ ). The difference between the stoichiometric relations shows that a larger amount of water is required to 


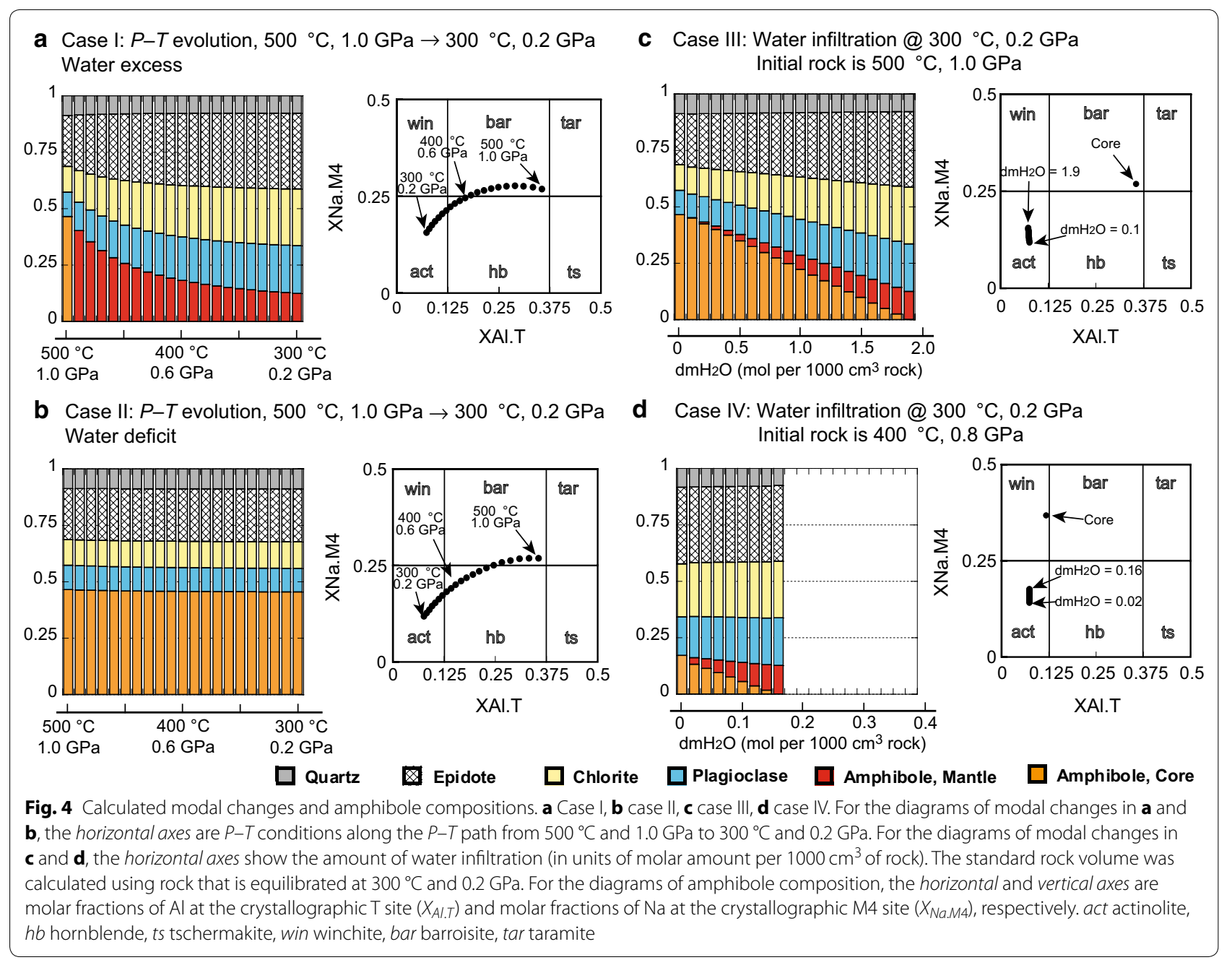

consume the same amount of core amphibole in case III than in case IV, because decomposition reactions of hightemperature core amphibole produce larger amounts of epidote and chlorite than is observed in the decomposition of low-temperature core amphibole.

\section{Discussion}

The proposed model can be regarded as an autonomous (self-contained) forward model that can predict how the system changes in response to changes in external conditions, because there is no need to assume changes in effective bulk compositions, as required in previous studies (e.g., Guiraud et al. 2001; Wei and Clarke 2011; Palin et al. 2014). The proposed model can predict the changes in mineral modes and compositions, including effective bulk compositions according to $P-T$ changes and the amount of water infiltration.

However, care should be taken that the conditions applied are those of actual metamorphic systems. The proposed method is based on a differential thermodynamic approach (Gibbs' method) that cannot predict the appearance of new phases. Thus, the application is limited to $P-T$ conditions at which we can assume that no additional phases are appearing, or that the molar amounts of newly appearing phases are small. These assumptions should be carefully checked by multiequilibrium modeling (e.g., Connolly 2009; Capitani and Petrakakis 2010) or by observations of natural systems. For the development of a unified treatment that incorporates broad $P-T$ ranges and various bulk rock compositions, the incorporation of the proposed modeling with multi-equilibrium models would be required.

Our formulation corresponds approximately to the mass-balance calculations in Okamoto and Toriumi (2005). In their formulation, only mass-balance equations are solved to obtain the extent of actinolite-forming reactions and the amount of rehydration, $d m_{H 2 O}$, by using mineral modes and the compositions of natural samples. However, our forward model employs equilibrium, stoichiometric, and mass-balance constraints to specify the 
rehydration reactions and the extent of the reactions according to changes in temperature, pressure, and water infiltration. The obtained stoichiometric relations for higher temperature original rock conditions (Eqs. 3, 4) are broadly in accordance with the conditions of actinolite-forming reactions in high- and low-grade zones in the Sanbagawa metamorphic rocks, as obtained by Okamoto and Toriumi (2005). This coincidence of numerical results and field observations supports the validity and effectiveness of our forward model.

In Okamoto and Toriumi (2005), parameter $Y_{a c t}$, which is defined as the volume fraction of actinolite to the total volume of amphibole, was introduced to evaluate the progress of the rehydration reactions in each sample of mafic schist. In this study, $Y_{a c t}$ can also be calculated in terms of the amount of core amphibole $\left(M^{\text {Amp,core }}\right)$ and mantle amphibole $\left(d M^{A m p, M t l}\right)$ for the conditions at $300{ }^{\circ} \mathrm{C}$ and $0.2 \mathrm{GPa}$, as:

$$
Y_{\text {act }}=\frac{M^{A m p, M t l}}{M^{\text {Amp,core }}+M^{A m p, M t l}} .
$$

Figure 5 illustrates the relationship between the calculated parameter $Y_{a c t}$ and the amount of water infiltration $d m_{\mathrm{H}_{2} \mathrm{O}}$ for cases III and IV. The parameter $Y_{\text {act }}$ increases continuously as a function of the amount of water infiltration and thus the extent of rehydration. The proposed forward analyses provide a theoretical grounding for the proposition by Okamoto and Toriumi (2005) that $Y_{\text {act }}$ can be used as an indicator of the extent of rehydration and amount of water infiltration.

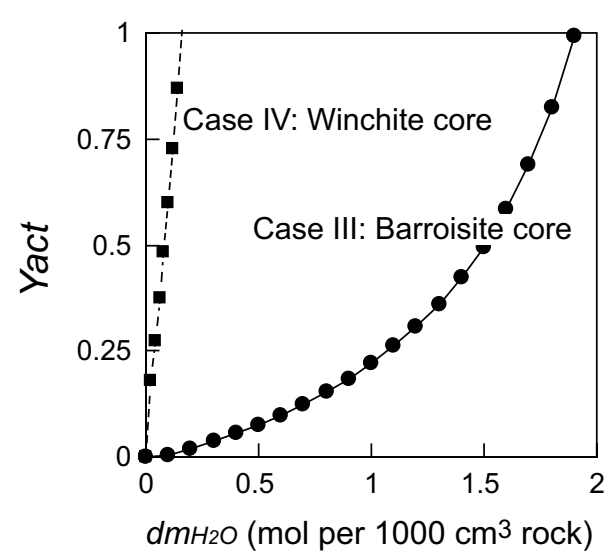

Fig. 5 Influence of fluid input $\left(d m_{\mathrm{H}_{2}} \mathrm{O}\right)$ on the volume fraction of actinolite relative to the total amphibole $Y_{\text {act, }}$, as defined by Okamoto and Toriumi (2005). The circles and line indicate the calculated result for case III, in which the original rock is equilibrated at $500^{\circ} \mathrm{C}$ and $1.0 \mathrm{GPa}$, and where the amphibole core is barroisite. The squares and dashed line indicate the calculated result for case IV, in which the original rock is equilibrated at $400^{\circ} \mathrm{C}$ and $0.8 \mathrm{GPa}$, and where the amphibole core is winchite
In this study, as well as Okamoto and Toriumi (2005), we assumed two distinct types of amphiboles, which are mantle amphibole that always has equilibrium compositions and core amphibole that has constant original non-equilibrium compositions. Such an assumption can only be a first-order approximation, given that minerals show remarkable continuous growth zoning during retrogression, which indicates that both equilibrium and non-equilibrium compositions have permanently changed. For a more precise analysis, we can improve the mass-balance equations, Eqs. (1) or (2), by incorporating the effects of fractional crystallization and compositional heterogeneity of non-equilibrium minerals.

The main results of our forward analyses of rehydration reactions show that changes in mineral compositions are mainly controlled by pressure and temperature, whereas changes in mineral modes are controlled by the amount of water infiltration. Even if the system contains large amounts of non-equilibrium phases, the equilibrated minerals have similar compositions as in the case of the usual global equilibrium model. The extent of net transfer in the reactions is proportional to the amount of water infiltration. This suggests that retrogressive hydration reactions require water infiltration to the system from external sources, as the porosity is generally considered to be small such that the rock contains little water.

These results indicate that high-grade metamorphic rocks are preserved if geofluids have not infiltrated into the system (e.g., Whitney and Davis, 2006; Vitale Brovarone et al. 2011). Retrogression of high-grade metamorphic rocks is localized to just around the system where geofluids can be sufficiently supplied. In contrast, a large amount of pervasive geofluid infiltration during retrograde stages eliminates the evidence of higher-grade peak stages. Recently published precise reconstructions of $P-T$ paths and detailed analyses of metamorphic textures show that some regional metamorphic rocks, including the Sanbagawa metamorphic belt, have undergone pervasive retrogressive hydration metamorphism during exhumation (e.g., Ota et al. 2004; Okamoto and Toriumi 2005; Maruyama et al. 2010). Our calculations theoretically support these observations and suggest that the existence and behavior of geofluids significantly affect the progress of retrogressive hydration metamorphism. Conversely, the progress of hydration reactions is a possible indicator of the existence and behavior of geofluids, as shown by the proposed forward model.

The proposed forward modeling can be used for inversion problems that estimate the water infiltration and $P-T$ conditions from bulk mineral compositions and changes in mineral modes and compositions. By incorporating the proposed forward modeling into a Bayesian inversion framework (Kuwatani et al. 2012), one could 
estimate temporal changes in the geofluid flux from mineral compositional zoning. Therefore, our proposed method is a potentially powerful tool for understanding the temporal and spatial evolution of the behavior of geofluids.

\section{Conclusions}

We have developed a new methodology for forward analysis of retrogressive rehydration reactions by improving the differential thermodynamic method (Spear 1993). The model includes changes in effective bulk compositions due to decomposition of non-equilibrated minerals and in the external water supply. Results of the forward analyses indicate that changes in mineral compositions are mainly controlled by pressure and temperature, whereas changes in mineral modes are controlled by the amount of water infiltration. In addition, the extent of rehydration reactions is proportional to the water supply, and thus, rehydration reactions do not proceed without a water supply. The numerical results are consistent with observations of natural examples of retrograde greenschist-facies rocks, which supports the validity and effectiveness of the proposed forward model.

\section{Additional file}

Additional file 1. Supplementary information including natural observations of rehydration reactions, basic equations for thermodynamic forward modeling and assumptions of the calculated system and the thermodynamic parameters.

\section{Authors' contributions}

TK and MT designed the research; TK performed the research; TK wrote the paper. Both authors read and approved the final manuscript.

\section{Author details \\ ${ }^{1}$ Department of Solid Earth Geochemistry, Japan Agency for Marine-Earth Sci- ence and Technology (JAMSTEC), 2-15 Natsushima-cho, Yokosuka 237-0061, Japan. ${ }^{2}$ PRESTO, Japan Science and Technology Agency (JST), 4-1-8 Honcho, Kawaguchi 332-0012, Japan. ${ }^{3}$ Innovation Promotion Office via Marine-Earth Science and Technology, Japan Agency for Marine-Earth Science and Technol- ogy (JAMSTEC), 3173-25, Showa-machi, Kanazawa-ku, Yokohama 236-0001, Japan.}

\section{Acknowledgements}

We wish to thank Prof. T. Takeshita, Dr. A. Okamoto and an anonymous reviewer for valuable comments. Discussions with Prof. H. Iwamori and Dr. M. Uno were thoughtful and constructive.

\section{Competing interests}

The authors declare that they have no competing interests.

\section{Funding}

This work was supported by JSPS KAKENHI Grant Numbers 25120005, 25280090, and 15K20864, and JST PRESTO.

Received: 18 November 2016 Accepted: 20 January 2017

Published online: 30 January 2017

\section{References}

Andersen T, Austrheim H, Burke E (1991) Fluid-induced retrogression of granulites in the Bergen Arcs, Caledonides of W. Norway: fluid inclusion evidence from amphibolite-facies shear zones. Lithos 27:29-42

Austrheim H (1987) Eclogitization of lower crustal granulites by fluid migration through shear zones. Earth Planet Sci Lett 81:221-232

Brodie KH, Rutter EH (1985) On the relationship between deformation and metamorphism, with special reference to the behaviour of basic rocks. In: Thompson AB, Rubie DC (eds) Metamorphic reactions: kinetics, textures and deformation. Adv Phys Geochem. pp 138-179

Centrella S, Austrheim H, Putnis A (2015) Coupled mass transfer through a fluid phase and volume preservation during the hydration of granulite: an example from the Bergen Arcs, Norway. Lithos 236-237:245-255

Connolly JAD (2009) The geodynamic equation of state: what and how. Geochem Geophys Geosys 10:Q10014. doi:10.1029/2009GC002540

De Capitani C, Petrakakis K (2010) The computation of equilibrium assemblage diagrams with Theriak/Domino software. Am Mineral 95:1006-1016. doi:10.2138/am.2010.3354

Gao J, Klemd R (2001) Primary fluids entrapped at blueschist to eclogite transition; evidence from the Tianshan meta-subduction complex in northwestern China. Contrib Mineral Petrol 142(1):1-14

Guiraud M, Powell P, Rebay G (2001) $\mathrm{H}_{2} \mathrm{O}$ in metamorphism and unexpected behaviour in the preservation of metamorphic mineral assemblages. J Metamorph Geol 19(4):445-454

Hacker BR, Abers GA, Peacock SM (2003) Subduction factory 1. Theoretical mineralogy, densities, seismic wave speeds, and $\mathrm{H}_{2} \mathrm{O}$ contents. J Geophys Res Solid Earth 108(B1):2030. doi:10.1029/2001JB001129

Holland TJB, Powell R (1998) An internally consistent thermodynamic data set for phases of petrological interest. J Metamorph Geol 16:309-343. doi:10.1111/j.1525-1314.1998.00140.x

Imon R, Okudaira T, Fujimoto A (2002) Dissolution and precipitation processes in deformed amphibolites: an example from the ductile shear zone of the Ryoke metamorphic belt, SW Japan. J Metamorph Geol 20:297-308

Inui M, Toriumi M (2004) A theoretical study on the formation of growth zoning in garnet consuming chlorite. J Petrol 45(7):1369-1392

Jamtveit B, Austrheim H, Malthe-Sorenssen A (2000) Accelerated hydration of the Earth's deep crust induced by stress perturbations. Nature 408:75-78

Kerrick DM, Connolly JAD (2001) Metamorphic devolatilization of subducted oceanic metabasalts: implications for seismicity, arc magmatism and volatile recycling. Earth Planet Sci Lett 189(1-2):19-29

Kohn MJ, Spear FS (2000) Retrograde net transfer reaction insurance for pressure-temperature estimates. Geology 28:1127-1130

Kuwatani T, Okamoto A, Toriumi M (2011) Thermodynamic forward modeling of progressive dehydration reactions during subduction of oceanic crust under greenschist facies conditions. Earth Planet Sci Lett 307:9-18

Kuwatani T, Nagata K, Okada M, Toriumi M (2012) Precise estimation of pressure-temperature paths from zoned minerals using Markov random field modeling: theory and synthetic inversion. Contrib Mineral Petrol 163(3):547-562

Maruyama S, Masago H, Katayama I, Iwase Y, Toriumi M, Omori S, Aoki K (2010) A new perspective on metamorphism and metamorphic belts. Gondwana Res 18(1):106-137

Miyashiro A (1961) Evolution of metamorphic belts. J Petrol 2:277-311

Okamoto A, Toriumi M (2001) Application of differential thermodynamics (Gibbs' method) to amphibole zonings in the metabasic system. Contrib Mineral Petrol 141(3):268-286

Okamoto A, Toriumi M (2004) Optimal mixing properties of calcic and subcalcic amphiboles: application of Gibbs' method to the Sanbagawa schists, SW Japan. Contrib Mineral Petrol 146(5):529-545

Okamoto A, Toriumi M (2005) Progress of actinolite-forming reactions in mafic schists during retrograde metamorphism: an example from the Sanbagawa metamorphic belt in central Shikoku, Japan. J Metamorph Geol 23(5):335-356

Okamoto A, Shimizu H (2015) Contrasting fracture patterns induced by volume-increasing and-decreasing reactions: implications for the progress of metamorphic reactions. Earth Planet Sci Lett 415:9-18

Omori S, Kamiya S, Maruyama S, Zhao D (2002) Morphology of the intraslab seismic zone and devolatilization phase equilibria of the subducting slab peridotite. Bull Earthq Res Inst Tokyo Univ 76:455-478 
Omori S, Kita S, Maruyama S, Santosh M (2009) Pressure-temperature conditions of ongoing regional metamorphism beneath the Japanese Islands. Gondwana Res 16:458-469

Ota T, Terabayashi M, Katayama I (2004) Thermobaric structure and metamorphic evolution of the Iratsu eclogite body in the Sanbagawa belt, central Shikoku, Japan. Lithos 73(1-2):95-126

Palin RM, St-Onge MR, Waters DJ, Searle MP, Dyck B (2014) Phase equilibria modelling of retrograde amphibole and clinozoisite in mafic eclogite from the Tso Morari massif, northwest India: constraining the $P-T$ $-\mathrm{M}\left(\mathrm{H}_{2} \mathrm{O}\right)$ conditions of exhumation. J Metamorph Geol 32:675-693. doi:10.1111/jmg.12085

Plunder A, Agard P, Dubacq B, Chopin C, Bellanger M (2012) How continuous and precise is the record of $P-T$ paths? Insights from combined thermobarometry and thermodynamic modelling into subduction dynamics (Schistes Lustres, W. Alps). J Metamorph Geol 30:323-346. doi:10.1111/j.1525-1314.2011.00969.x

Powell R, Holland T, Worley B (1998) Calculating phase diagrams involving solid solutions via non-linear equations, with examples using THERMOCALC. $J$ Metamorph Geol 16(4):577-588

Putnis A (2009) Mineral replacement reactions. Rev Mineral Geochem 70:87-124

Putnis A, Austrheim H (2010) Fluid-induced processes: metasomatism and metamorphism. Geofluids 10:254-269

Putnis A, John T (2010) Replacement processes in the Earth's crust. Elements 6:159-164

Rubie DC (1986) The catalysis of mineral reactions by water and restrictions on the presence of aqueous fluid during metamorphism. Mineral Mag 50(357):399-415

Spear FS (1993) Metamorphic phase equilibria and pressure-temperaturetime paths. Mineralogical Society of America, New York

Stüwe K (1997) Effective bulk composition changes due to cooling: a model predicting complexities in retrograde reaction textures. Contrib Mineral Petrol 129(1):43-52

Uno M, Iwamori H, Nakamura H, Yokoyama T, Ishikawa T, Tanimizu M (2014) Elemental transport upon hydration of basic schists during regional metamorphism: geochemical evidence from the Sanbagawa metamorphic belt, Japan. Geochem J 48:29-49

Vernon RH (2004) A practical guide to rock microstructures. Cambridge University Press, Cambridge

Vitale Brovarone A, Beyssac O (2014) Lawsonite metasomatism: a new route for water to the deep Earth. Earth Planet Sci Lett 393:275-284 doi:10.1016/j.epsl.2014.03.001

Vitale Brovarone A, Groppo C, Hetenyi G, Compagnoni R, Malavieille J (2011) Coexistence of lawsonite-bearing eclogite and blueschist: phase equilibria modelling of Alpine Corsica metabasalt and petrological evolution of subducting slabs. J Metamorph Geol 29:583-600

Wallis SR, Anczkiewicz R, Endo S, Aoya M, Platt JP, Thirlwall M, Hirata T (2009) Plate movements, ductile deformation and geochronology of the Sanbagawa belt, SW Japan: tectonic significance of 89-88 Ma Lu-Hf eclogite ages. J Metamorph Geol 27:93-105

Wei CJ, Clarke GL (2011) Calculated phase equilibria for MORB compositions: a reappraisal of the metamorphic evolution of lawsonite eclogite. J Metamorph Geol 29:939-952. doi:10.1111/j.1525-1314.2011.00948.x

Whitney DL, Davis PB (2006) Why is lawsonite eclogite so rare? Metamorphism and preservation of lawsonite eclogite, Sivrihisar, Turkey. Geology 34:473-476

Yang TN (2004) Retrograded textures and associated mass transfer: evidence for aqueous fluid action during exhumation of the Qinglongshan eclogite, Southern Sulu ultrahigh pressure metamorphic terrane, eastern China. J Metamorph Geol 22(7):653-669

Yardley BWD (2009) The role of water in the evolution of the continental crust. J Geol Soc 166:585-600 doi:10.1144/0016-76492008-101

Yardley BWD, Rhede D, Heinrich W (2014) Rates of retrograde metamorphism and their implications for the rheology of the crust: an experimental study. J Petrol 55:623-641. doi:10.1093/petrology/egu001

\section{Submit your manuscript to a SpringerOpen ${ }^{\odot}$ journal and benefit from:}

- Convenient online submission

- Rigorous peer review

- Immediate publication on acceptance

- Open access: articles freely available online

- High visibility within the field

- Retaining the copyright to your article

Submit your next manuscript at springeropen.com 